\title{
Analysis of components effecting free convection intensity in steel rectangular sections
}

\author{
RAFAŁ WYCZÓŁKOWSKI ${ }^{1}$
}

Czestochowa University of Technology, Faculty of Production Engineering and Materials Technology, Armii Krajowej 19, 42-200 Częstochowa, Poland

\begin{abstract}
Free convection is one of the heat transfer modes which occurs within the heat-treated bundles of steel rectangular section. A comprehensive study of this phenomenon is necessary for optimizing the heating process of this type of charge. The free convection intensity is represented by the Rayleigh number Ra. The value of this criterion depends on the following parameters: the mean section temperature, temperature difference within the section, kinematic coefficient of viscosity, volume expansion coefficient and the Prandtl number. The paper presents the analysis of the impact of these factors on free convection in steel rectangular sections. The starting point for this analysis were the results of experimental examinations. It was found that the highest intensity of this process occurs for the temperature of $100{ }^{\circ} \mathrm{C}$. This is mainly caused by changes in the temperature difference observed in the area of sections and changes in kinematic coefficient of viscosity of air. The increase in the value of the Rayleigh number criterion at the initial stage is attributable to changes in the parameter of temperature difference within the section. After exceeding $100^{\circ} \mathrm{C}$, the main effect on convection is from changes in air viscosity. Thus, with further increase in temperature, the Rayleigh number starts to decline rapidly despite further rise in the difference in temperature.
\end{abstract}

Keywords: Free convection; Rayleigh number; Section bundles; Effective thermal conductivity; Heat treatment

${ }^{1}$ E-mail: rwyczolkowski@wip.pcz.pl 


\section{Nomenclature}

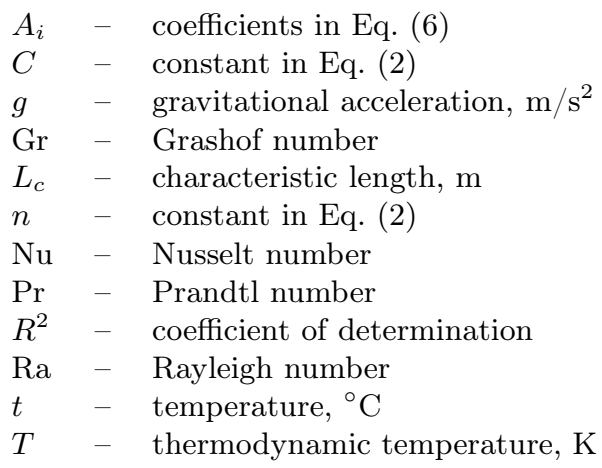

\section{Greek symbols}

$\beta \quad-\quad$ volume expansion coefficient, $1 / \mathrm{K}$

$\Delta t \quad-\quad$ temperature difference, $\mathrm{K}$

$\nu \quad-\quad$ kinematic coefficient of fluid viscosity, $\mathrm{m}^{2} / \mathrm{s}$

\section{Subscripts}

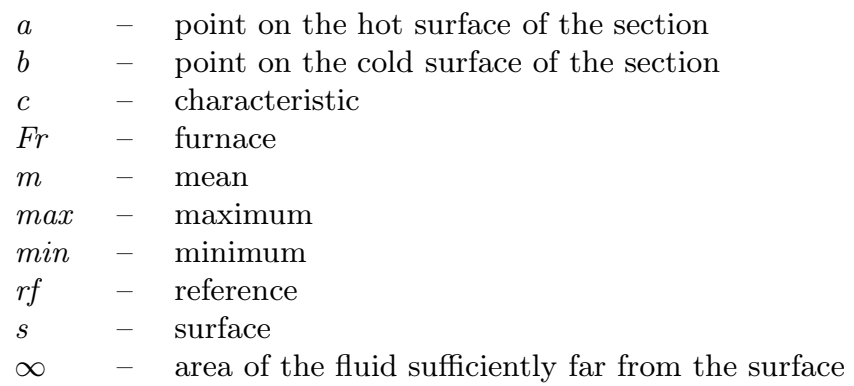

\section{Introduction}

Free convection is the mode of heat transfer which is connected with the motion of fluid caused by the heterogeneity of its density in a gravitational field $[1,2]$. The heterogeneity of density in this case is caused by a variation of the temperature field of the fluid. Due to the geometry of the area in which this phenomenon occurs, we distinguish free convection in closed space (internal flow) and free convection in open space (external flow) [3,4]. This division is a very important because influence of the dimensions and geometry of the heat transfer area have essential significance to the free convection process. If this effect does not occur or is negligibly small, the space is considered as open [5]. 
The above types of free convection differ from each other by specific nature of the occurring phenomena. This differentiation is reflected in the approach to their theoretical analysis. In the case of free convection in open space the fluid motion occurs mainly next to the surface of the solid body in the boundary layer area. Outside the boundary layer, fluid motion is insignificant and essentially does not have any effect on heat transfer. Therefore, it was assumed in theoretical investigations that in this case the fluid outside the boundary layer is stationary and does not affect the flow generation.

In the case of free convection in a confined space, at the edges of the area are formed the boundary layers. These layers reduce the space in which rest of the fluid is closed. This space is called the nucleus. The shape and size of this nucleus depend on the geometry of heat exchange area and geometry of boundary layers. At the same time there is a mutual conditioning of the flows in nucleus and in boundary layers. This conditioning constitutes the essential difficulty for theoretical analysis of this issue.

The phenomena of free convection in the closed space concern, among other things, such problems as: heat exchange in rooms, flows in the channels and ducts in the temperature field, temperature distributions and the fluid motion in the containers, solidification of castings and ingots. A special case of a free convection in the limited area is the convection heat transfer occurred in the inner spaces of the steel rectangular sections which are heat treated [6]. During these operations the sections are usually heated in bundles, examples of which are shown in Fig. 1. Heating of the sections in such a form is caused by the fact that the stock in this form ensures the most efficient utilization of the furnaces workspace. In addition, sections tied as bundles are convenient in transport.

Optimization of heat treatment processes requires the knowledge about thermal properties of heated elements [7]. Section bundle due to the geometrical structure is a two-phase porous medium. For this reason, its basic thermal property is the effective thermal conductivity, $k_{e f}[8]$. This parameter expresses quantitatively the medium ability to energy transfer by different modes of heat flow and is commonly used in the theory of porous media [9-11]. The value of $k_{e f}$ coefficient of a section bundle depends on the intensity of particular heat transfer modes which occur during heat treatment. One of these modes is a free convection of the gas that occurs in the inner spaces of the individual sections. Hence the knowledge about the course of the free convection phenomenon in the section bundle is necessary 

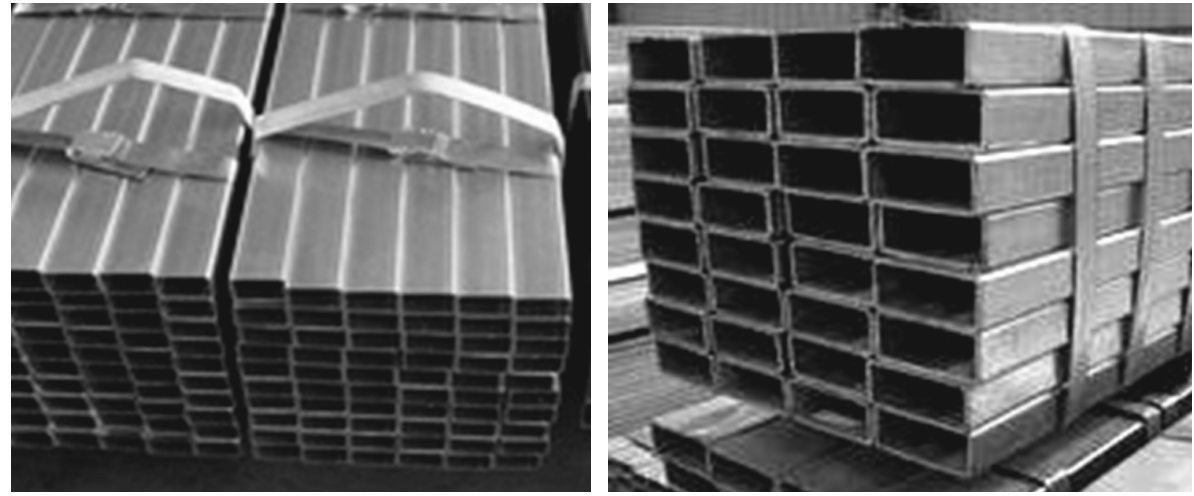

Figure 1: Examples of the bundles of steel rectangular sections.

in analytical determination of the coefficient $k_{e f}$ of such medium.

The article presents the analysis of free convection occurring in the area of rectangular steel sections heated in bundles. For this purpose the Rayleigh number was used, which is a dimensionless criterion of similarity for free convection. The starting point for calculations were the results of experimental tests. These tests were carried out on the section bundle samples heated in a laboratory box-type furnace.

\section{Rayleigh number as the free convection parameter}

The key problem of the theoretical research related to the heat transfer is the solution of equations representing mathematical model of the considered process. Mathematical description of convection phenomenon includes the continuity, momentum and energy equations [1-4]. These equations must be completed by the uniqueness conditions, which include equations describing dependences of the fluid physical properties on the temperature and the boundary and initial conditions. This makes that at consideration of the convection phenomenon we have to solve a system of coupled nonlinear partial differential equations. Solving this system is possible only through approximation, after making a number of simplifying assumptions [4].

Due to the above difficulties with the analysis of free convection, the theory of similarity is often used $[1,2,12]$. This method consists in reduction of differential equations that describe the phenomenon analyzed to the 
dimensionless form. This approach yields dimensionless parameters termed numbers of similarity. The dimensionless parameter that represents the natural convection effects is the Grashof number $[3,12]$

$$
\mathrm{Gr}=\frac{g \beta\left(t_{s}-t_{\infty}\right) L_{c}^{3}}{\nu^{2}} .
$$

This parameter represents the ratio of the buoyancy force to viscous force acting on the fluid. This means that the role played by Reynolds number in forced convection is played by the Grashof number in natural convection. As such the Grashof number provides the criterion in determining whether the fluid flow is laminar or turbulent in natural convection.

The simple empirical correlations for the average Nusselt number in free convection are of the form [12]

$$
\mathrm{Nu}=C(\mathrm{GrPr})^{n}=C(\mathrm{Ra})^{n},
$$

where $\mathrm{Ra}$ is the Rayleigh number, which is the product of Grashof and Prandtl numbers

$$
\mathrm{Ra}=\mathrm{GrPr}=\frac{g \beta\left(t_{s}-t_{\infty}\right) L_{c}^{3}}{\nu^{2}} \operatorname{Pr} .
$$

This means, that the Rayleigh number $\mathrm{Ra}$ is the dimensionless parameter for free convection. The Rayleigh number for an enclosure (internal flow) is determined from [12]

$$
\mathrm{Ra}=\mathrm{GrPr}=\frac{g \beta\left(t_{a}-t_{b}\right) L_{c}^{3}}{\nu^{2}} \operatorname{Pr},
$$

where the characteristic length $L_{c}$ is the distance between the hot and cold surfaces, and $t_{a}$ and $t_{b}$ are the temperatures of the hot and cold surfaces, respectively. When for heat transfer in enclosure $\mathrm{Ra}>1700$, the buoyant forces overcomes the fluid resistance and free convection currents are initiated. For $\mathrm{Ra}>3 \times 10^{5}$ the fluid motion in enclosure becomes turbulent [12].

From the geometrical point of view steel section can be treated as the enclosure. Hence Rayleigh number allows for a very simple assessment of the free convection intensity which occurs inside the heated sections.

\section{Experimental tests}

The problem of free convection in the area of steel sections has been the focus of several previous studies [13-15]. This phenomenon has been analyzed 
in both steady and unsteady conditions. It was found that the Rayleigh number for convection inside steel sections obtained for the unsteady conditions is by an order of magnitude greater than the values recorded under steady conditions. Since heating of steel section bundles during heat treatment is an unsteady process, the value of the Rayleigh number obtained for unsteady conditions seems to be interesting from the practical point of view. It was also demonstrated that, regardless of the heat transfer conditions (steady or unsteady), maximal values of Ra parameter are observed over a relatively narrow range of temperatures of about $70-90{ }^{\circ} \mathrm{C}$. Further increase in mean temperature of section, $t_{m}$, regardless of the temperature difference in its area, $\Delta t$, leads to a rapid decline in the Ra parameter.

Equation (4) shows that Ra number is affected by the four temperaturedependent parameters: volume expansion coefficient, $\beta$, temperature difference, $\Delta t$, kinematic coefficient of viscosity, $\nu$ and the Prandtl number, Pr. Experimental examinations were needed to evaluate the effect of these parameters on free convection that occurs inside heated sections. The experiments involved heating the steel section specimens in a laboratory box-type furnace with internal chamber dimensions of $250 \mathrm{~mm} \times 300 \mathrm{~mm} \times 1000 \mathrm{~mm}$ (height $\times$ width $\times$ length). The heating elements in the furnace were provided by coils of resistant wire located along side walls of the chamber. The examinations were carried out for the range of temperature of $25-700{ }^{\circ} \mathrm{C}$, which is the range typical to the most of steel products heat treatment operations [7]. Heating was carried out in the air atmosphere.

Two bundles were examined, made of square sections with external dimensions of $60 \mathrm{~mm}$ and $80 \mathrm{~mm}$ and wall thickness of $3 \mathrm{~mm}$. Section length was $800 \mathrm{~mm}$. The examinations consisted in the measurement of the temperature in the areas of the selected sections. Measurement points were located in the half of the section length on the opposite walls with respect to the heat flow direction. This allowed for obtaining a hot point (denoted as $a$ ) and cold point (denoted as $b$ ). Measurements for the $60 \mathrm{~mm}$ section bundle were carried out in the area of two adjacent sections, denoted as $I$ and $I I$. This bundle was composed of sixteen sections with four layers. Furthermore, in the $80 \mathrm{~mm}$ section bundle, measurements were carried out only in the area of a single section of the second layer. This bundle was composed of nine sections with three layers. Small dimensions of the furnace chamber caused that the size of the this bundle was limited to only three sections in the layer. Location of the temperature measurement points in individual bundles is presented in Fig. 2. With heating elements fixed 
inside the furnace chamber, it can be adopted that heat transfer in the area of bundles was one-dimensional, which is denoted in Fig. 2 with arrows.

(a)

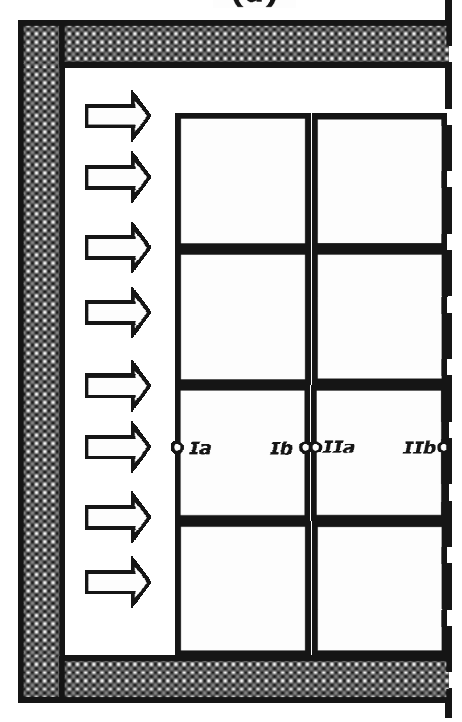

(b)

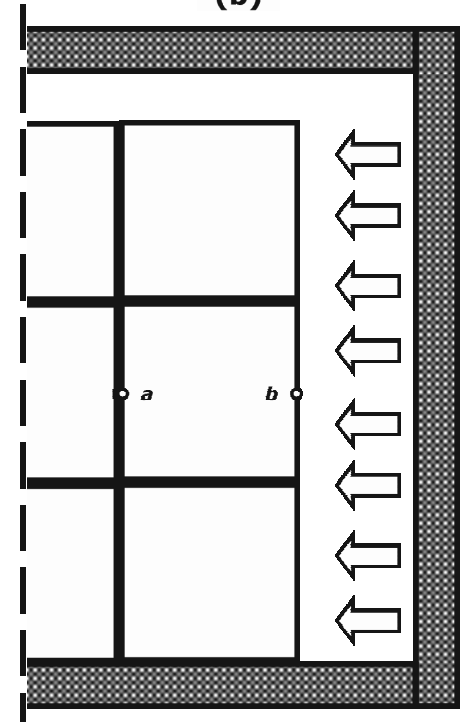

Figure 2: Location of temperature measuring points inside tested samples: a) bundle of the sections $60 \mathrm{~mm}$, b) bundle of the sections $80 \mathrm{~mm}$ (arrows indicate the direction of heat flow to the charge).

The temperature measurement system was comprised of a digital microprocessor thermometer (EMT 200), multichannel switch (PMP 201) and jacked-thermocouple (type $\mathrm{K}$ ) with diameter of $1 \mathrm{~mm}$. The system allowed for temperature measurement with accuracy of $0.5^{\circ} \mathrm{C}$ [16]. Measurement tips of thermocouples were fixed in small grooves made on external surfaces of the sections. Heat-resistant silicone was used to fix the tips. Figure 3 presents one of the bundles inside the furnace chamber and fixing of one of the thermocouples to the section surface. Temperatures measured during the heating process were recorded at 5-minute intervals.

Heating was continued until the final temperature, $t_{F r}$, was reached (set at $750^{\circ} \mathrm{C}$ ). With the $60 \mathrm{~mm}$ sections bundle, this temperature was reached in $50 \mathrm{~min}$. During heating of the $80 \mathrm{~mm}$ section bundle due to higher porosity of the charge and, consequently, its lower mass, final temperature was obtained after $25 \mathrm{~min}$. Figure 4 illustrates changes in the temperature in the furnace chamber, $t_{F r}$, and temperatures at the measurement points of the bundles studied. As can be seen from the figure, heating of bundles 
(a)

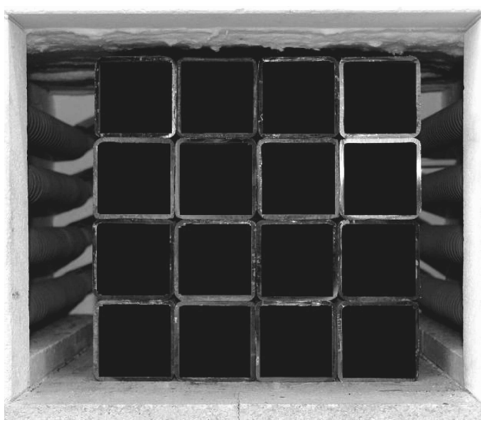

(b)

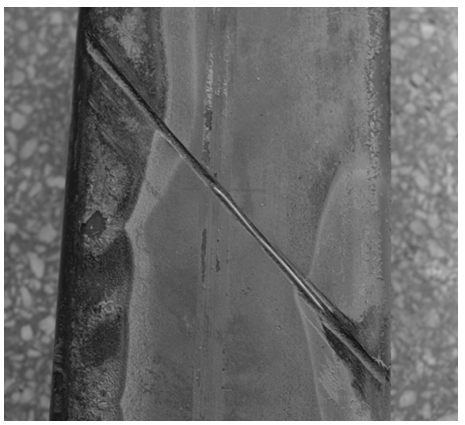

Figure 3: (a) View of the bundle of $60 \mathrm{~mm}$ section inside the furnace chamber - on the side walls are visible the heating elements, (b) image illustrating fixing of the thermocouple to the section surface.

(a)

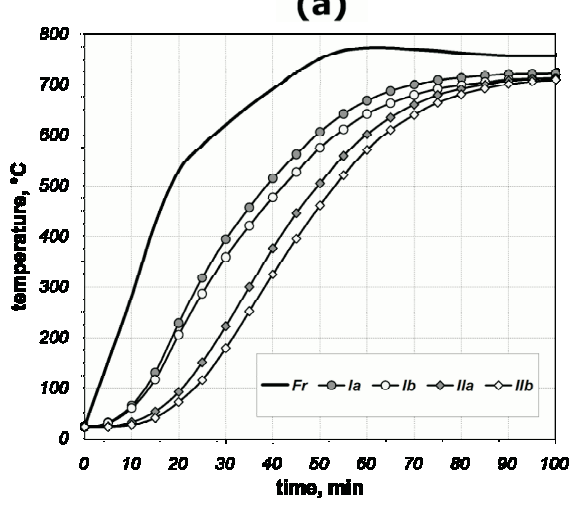

(b)

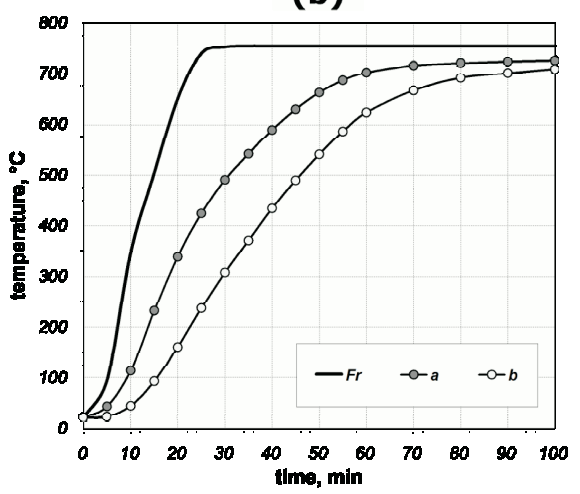

Figure 4: Changes of the furnace chamber temperature $t_{F r}$ and the temperatures of the measuring points of the samples: (a) results for the $60 \mathrm{~mm}$ section bundle, (b) results for the $80 \mathrm{~mm}$ section bundle.

to reach the target final temperature $\left(700^{\circ} \mathrm{C}\right)$ in both cases took around $100 \mathrm{~min}$.

From the standpoint of the analysis of the Rayleigh number, the temperature difference, $\Delta t$, between the hot point and cold point in the heated sections seem to be critical. Changes in the parameter, $\Delta t$, obtained for $60 \mathrm{~mm}$ sections and $80 \mathrm{~mm}$ section are presented in Figs. 5 and 6 , respectively. Figures 5(a) and 6(a) illustrate changes in the parameter $\Delta t$ with time of heating, whereas Figs. 5(b) and 6(b) illustrate these changes with respect to mean section temperature, $t_{m}$. The temperature $t_{m}$ for each 
section was calculated as the arithmetic mean of its temperature in points $a$ and $b$

$$
t_{m}=0.5\left(t_{a}+t_{b}\right)
$$

The maximum value of $\Delta t$ parameter for the $60 \mathrm{~mm}$ section bundle for both sections was observed after $40 \mathrm{~min}$ of heating. For the section $I$, this parameter was $51^{\circ} \mathrm{C}$, obtained for the mean temperature of $350^{\circ} \mathrm{C}$. For the section $I I$, this value was $37.5^{\circ} \mathrm{C}$, reached for the mean temperature of $496^{\circ} \mathrm{C}$. A substantially greater temperature difference was found for the $80 \mathrm{~mm}$ section. The maximum value of the parameter $\Delta t$ in this case was $188^{\circ} \mathrm{C}$, with mean temperature of $331^{\circ} \mathrm{C}$.

(a)

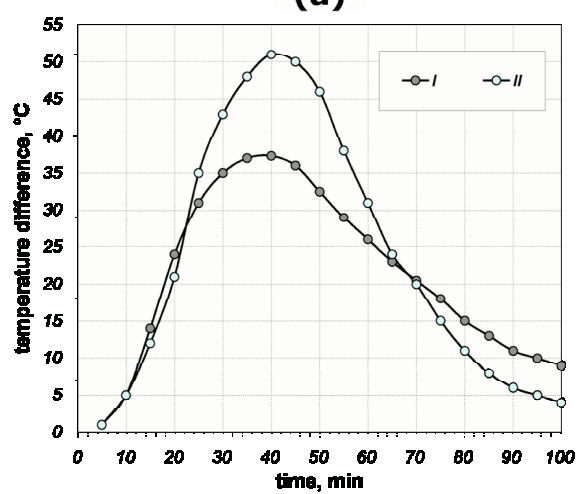

(b)

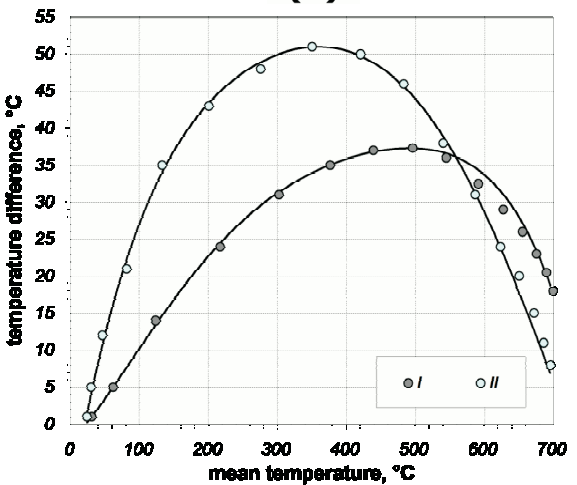

Figure 5: Temperature differences $\Delta t$ within the $60 \mathrm{~mm}$ sections: (a) changes as a function of the heating time, (b) changes as a function of the section mean temperature $t_{m}$.

For the purposes of further analysis, changes in the temperature difference of the sections vs. mean temperature (presented in Figs. 5(b) and $6(\mathrm{~b})$ ) were approximated with regression equations. The best fit of the approximated values to the measurement data in all the cases were obtained for the equations in the form of the 5 th order polynomial

$$
\Delta t=A_{1} t_{m}^{5}+A_{2} t_{m}^{4}+A_{3} t_{m}^{3}+A_{4} t_{m}^{2}+A_{5} t_{m}+A_{6} .
$$

Values of coefficients $A_{1}-A_{6}$ and coefficient of determination $R^{2}$ obtained for individual sections are presented in Tab. 1 . 
(a)

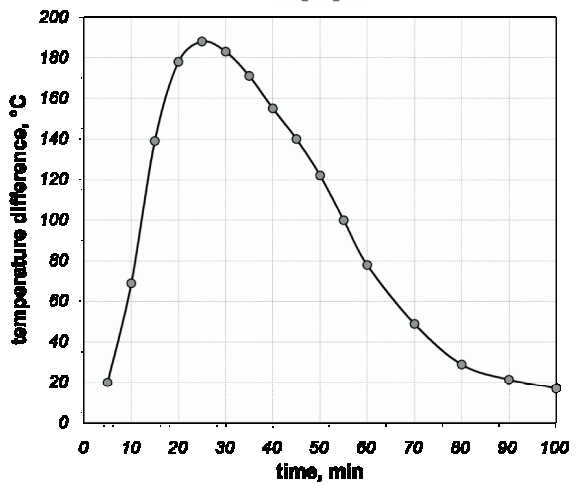

(b)

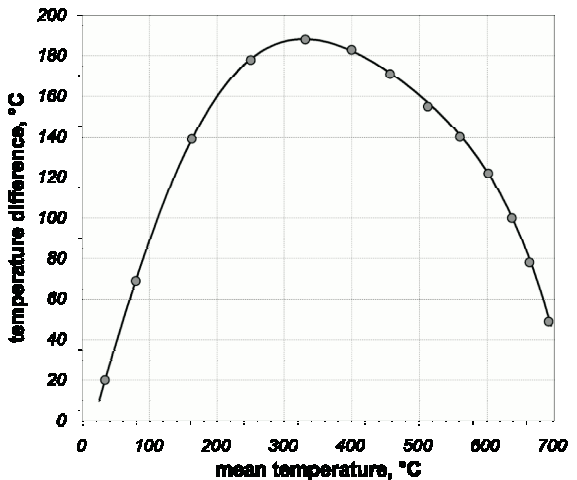

Figure 6: Temperature differences $\Delta t$ within the $80 \mathrm{~mm}$ section: (a) changes as a function of the heating time, (b) changes as a function of the section mean temperature $t_{m}$.

Table 1: Values of coefficients $A_{1}-A_{6}$ from Eq. (7) and coefficient $R^{2}$ for analyzed sections.

\begin{tabular}{|c|c|c|c|}
\hline Section & $60 \mathrm{~mm} I$ & $60 \mathrm{~mm} I I$ & $80 \mathrm{~mm}$ \\
\hline \hline$A_{1}$ & $-2.67 \times 10^{-12}$ & $3.13 \times 10^{-12}$ & $-1.34 \times 10^{-11}$ \\
\hline$A_{2}$ & $4.28 \times 10^{-9}$ & $-6.61 \times 10^{-9}$ & $2.11 \times 10^{-8}$ \\
\hline$A_{3}$ & $-2.53 \times 10^{-6}$ & $5.17 \times 10^{-6}$ & $-1.04 \times 10^{-5}$ \\
\hline$A_{4}$ & 0.00049 & -0.00222 & $-3.44 \times 10^{-5}$ \\
\hline$A_{5}$ & 0.0994 & 0.5568 & 1.1726 \\
\hline$A_{6}$ & -2.532 & -11.03 & -19.472 \\
\hline$R^{2}$ & 0.998 & 0.999 & 0.998 \\
\hline
\end{tabular}

\section{Analytical calculations}

Apart from the temperature difference $\Delta t$, the equation that defines the Rayleigh number also contains three temperature-dependent parameters, namely volume expansion coefficient, $\beta$, kinematic coefficient of viscosity, $\nu$, and Prandtl number, Pr. Coefficient $\beta$ of an ideal gas at the thermodynamic temperature, $T$, is equivalent to the inverse of the temperature $[3,12]$

$$
\beta=\frac{1}{T}
$$


In our case, the coefficient $\beta$ was calculated from

$$
\beta=\frac{1}{T_{r f}}=\frac{1}{t_{r f}+273},
$$

where the temperature $t_{r f}$ is termed the reference temperature, which is the arithmetic mean temperature of the hot and cold fluid. The temperature $t_{r f}$ used for calculation of other thermal properties of air was adopted as equal $t_{m}$

Changes in kinematic coefficient of viscosity and Prandtl number for air vs. temperature are presented in Fig. 7. The data were found in the literature [12]. The increase in air viscosity with temperature is given by the equation

$$
\nu=6.8 \times 10^{-8} t_{m}^{2}+9.52 \times 10^{-8} \times t_{m}+1.3 \cdot 10^{-5} .
$$

Furthermore, changes in Prandtl number for the discussed temperature range is given by a 4 th order polynomial

$\operatorname{Pr}=3.16 \times 10^{-13} t_{m}^{4}+8.76 \times 10^{-10} t_{m}^{3}+8.97 \times 10^{-7} t_{m}^{2}-0.00032 t_{m}+0.738$.

(a)

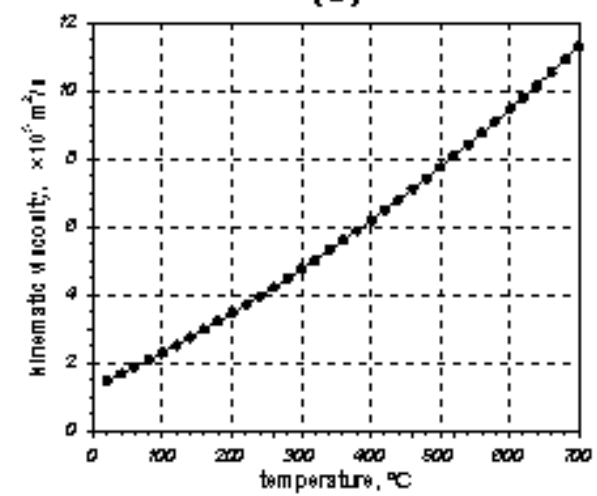

(b)

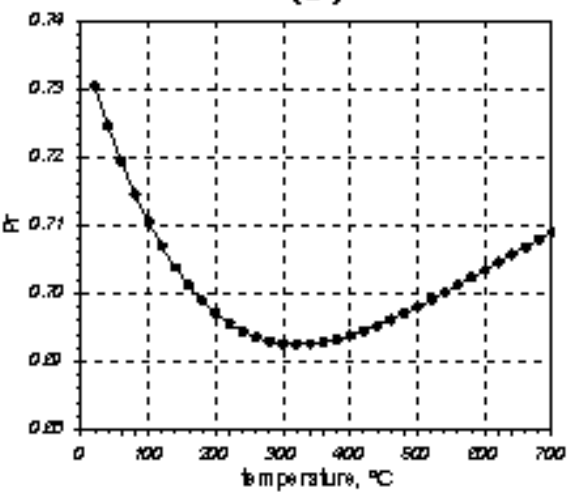

Figure 7: Temperature changes of: a) kinematic coefficient of viscosity, b) Prandtl number, of air.

The results of calculations of the Rayleigh number for the analyzed three sections obtained from the Eqs. (7) and (8)-(10) are presented in Fig. 8. Figure 8(a) illustrates the values concerning the $60 \mathrm{~mm}$ sections. Maximal value of Ra parameter for the section $I$ was observed for the mean temperature of $110^{\circ} \mathrm{C}$ and was $5.6 \times 10^{4}$. For the section $I I$, this value was found 
for the mean temperature of $80^{\circ} \mathrm{C}$ and was $15.3 \times 10^{4}$. Almost three-time greater maximum value of Ra criterion for the section $I I$ was caused by a higher temperature difference. Furthermore, the parameter $\Delta t$ for both sections has a different profile in the function of mean temperature. Variation of the results obtained for both sections indicates that the Rayleigh number is affected by both parameter $\Delta t$ and its changes with respect to mean temperature. Figure $8(\mathrm{~b})$ presents the results of calculations of Ra parameter obtained for the $80 \mathrm{~mm}$ section. Maximal value in this case was observed for the mean temperature of $85^{\circ} \mathrm{C}$ and was $126.8 \times 10^{4}$. Compared to the result obtained for the section $60 \mathrm{~mm} \mathrm{II} \mathrm{(also} \mathrm{shown} \mathrm{in} \mathrm{Fig.} \mathrm{8(b)} \mathrm{for}$ comparison), this value is by one order of magnitude greater. Comparison of the results obtained for both sections should also take into consideration their different dimensions. For $80 \mathrm{~mm}$ section, characteristic dimension $L_{c}$ is $0.75 \mathrm{~mm}$, whereas for the $60 \mathrm{~mm}$ section, this dimension is $54 \mathrm{~mm}$. As can be seen, the increase in the parameter, $L_{c}$, by $27 \%$ contributes to a ten-fold increase in the value of the Ra number. This happens because the dimension $L_{c}$ in the equation of the Rayleigh number occurs with the power of 3. Therefore, the dimensions of the space where free convection occurs are critical for this type of heat transfer. Changes in the parameter Ra shown in Fig. 8 for all three sections have a similar and very characteristic profile. A very dynamic increase is observed from the initial temperature to the value of around $80-100^{\circ} \mathrm{C}$. After reaching the maximal value, further increase in temperature is followed mainly by a similarly rapid decline. Over the range of temperature of $200-250^{\circ} \mathrm{C}$ the Rayleigh number values decreases by half. This demonstrates that the intensity of free convection during section heating in this process is varied with time. The highest intensity of this phenomenon is observed at the initial stage of heating, where mean temperature of the sections does not exceed $100^{\circ} \mathrm{C}$.

In order to achieve the aim of the study, the attempt was also made to verify the changes of which parameters (termed in the title as components) affect the value of Ra number. A series of calculations were carried out for this purpose. A constant value was adopted for each parameter during the calculations. Calculations were carried out for each parameter and for three values: maximal, mean and minimal. The values adopted for calculations are presented in Tab. 2. The minimal values for the temperature difference for both sections were adopted as equal to mean temperature, $t_{m}$, for which the maximum was observed for the parameter Ra. 
(a)

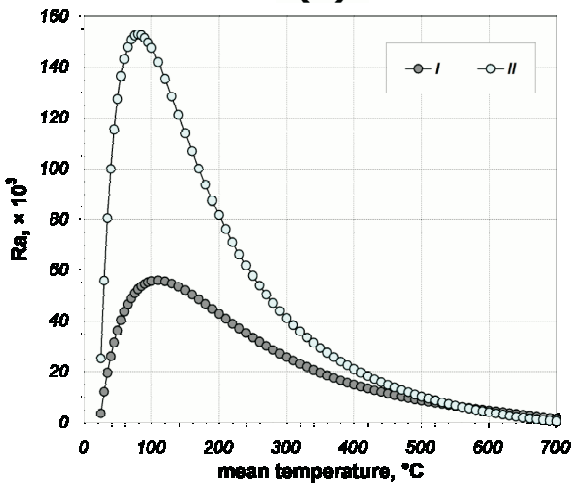

(b)

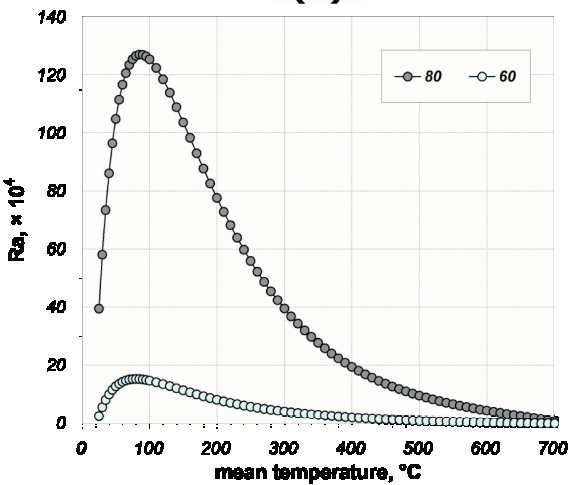

Figure 8: Calculation results of the Rayleigh number: (a) values for the sections $60 \mathrm{~mm}$, (b) values for the section $80 \mathrm{~mm}$ and section $60 \mathrm{~mm} \mathrm{II}$.

Table 2: Maximal, mean and minimal values of the components used in calculations.

\begin{tabular}{|c|c|c|c|c|c|}
\hline Parameter & $\operatorname{Pr}$ & $\nu, \mathrm{m}^{2} / \mathrm{s}$ & $\beta, 1 / \mathrm{K}$ & $\Delta t_{60},{ }^{\circ} \mathrm{C}$ & $\Delta t_{80},{ }^{\circ} \mathrm{C}$ \\
\hline \hline maximal & 0.729 & $11.3 \times 10^{-5}$ & 0.0033557 & 50.9 & 188.2 \\
\hline mean & 0.703 & $5.52 \times 10^{-5}$ & 0.0018813 & 34.3 & 128.2 \\
\hline minimal & 0.692 & $1.54 \times 10^{-5}$ & 0.0010277 & 21.6 & 69.6 \\
\hline
\end{tabular}

Figure 9 presents the results of calculations obtained for constant values of the Prandtl number. As can be seen, changes in this parameter affect the Rayleigh number only to an insignificant degree. This is due to the fact that changes in the Pr number for air in the analyzed range of temperature are insignificant. With respect to the maximal value of Pr number, these changes are only $1.4 \%$.

The results of calculations of the Rayleigh number obtained for constant kinematic coefficient of viscosity are presented in Fig. 10. It can be noted that changes in this parameter significantly affect the value of the discussed criterion. The increase in air viscosity substantially reduces the Ra number, thus decreasing the intensity of free convection. This effect is caused by an increase in resistance for fluid flow. Furthermore, curves in these charts have entirely different profiles compared to the curves from Fig. 8. This suggests that the characteristic profile of curves in Fig. 8 can be attributable, among other things, to changes in air viscosity with temperature. Maximal 
values of the Ra number in this case occur at the temperature of $210^{\circ} \mathrm{C}$, i.e., they are shifted by over $100^{\circ} \mathrm{C}$ compared to the maximal values from Fig. 8. Since the coefficient $\nu$ in the Rayleigh number equation occurs with the power of two, a relatively small decline in this parameter significantly increases the value of Ra.

(a)

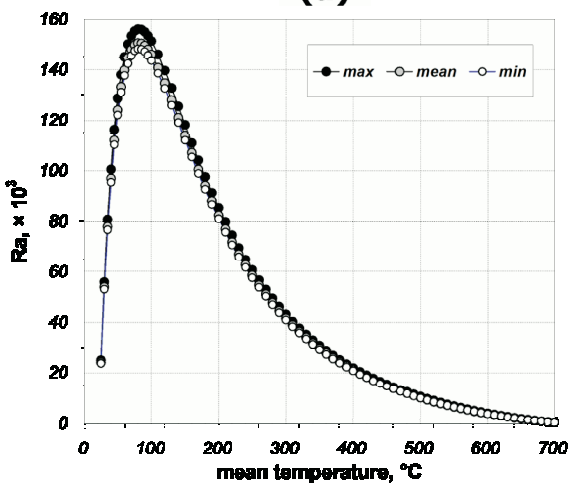

(b)

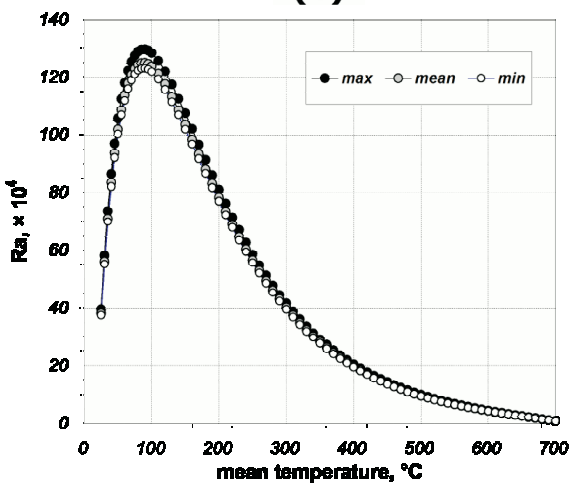

Figure 9: The Rayleigh number obtained for fixed values of the Prandtl number: (a) values for the section $60 \mathrm{~mm} \mathrm{II}$, (b) values for the section $80 \mathrm{~mm}$.

(a)

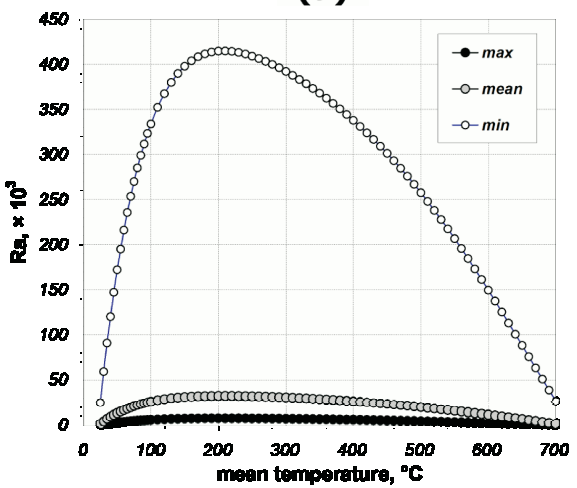

(b)

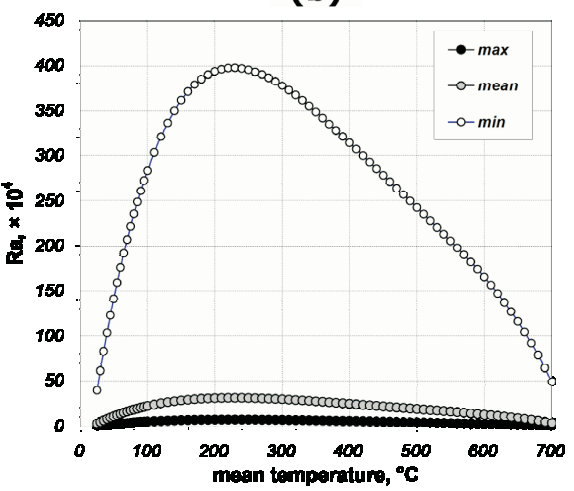

Figure 10: The Rayleigh number obtained for fixed values of the kinematic coefficient of viscosity, $\nu$ : (a) values for the section $60 \mathrm{~mm} \mathrm{II}$, (b) values for the section $80 \mathrm{~mm}$.

Figure 11 presents the results of calculations obtained for constant volume expansion coefficient, $\beta$. Changes in this parameter have a noticeable effect on the Ra number. This effect, however, is not that substantial as 
it was the case in kinematic coefficient of viscosity. Importantly, shape of curves in this figure is similar to the curves in Fig. 8. Therefore, changes in the coefficient $\beta$ do not affect the intensity of convection with respect to temperature.

(a)

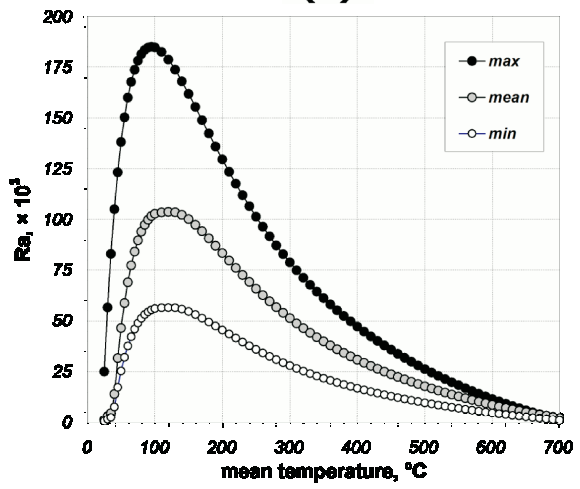

(b)

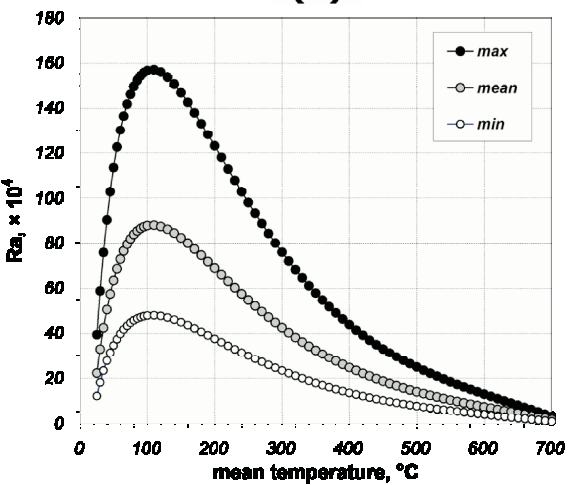

Figure 11: The Rayleigh number obtained for fixed values of the volume expansion coefficient $\beta$ : (a) values for the section $60 \mathrm{~mm} \mathrm{II}$, (b) values for the section $80 \mathrm{~mm}$.

(a)

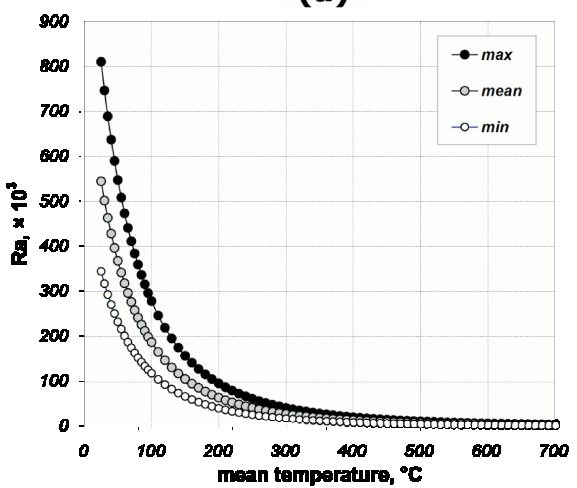

(b)

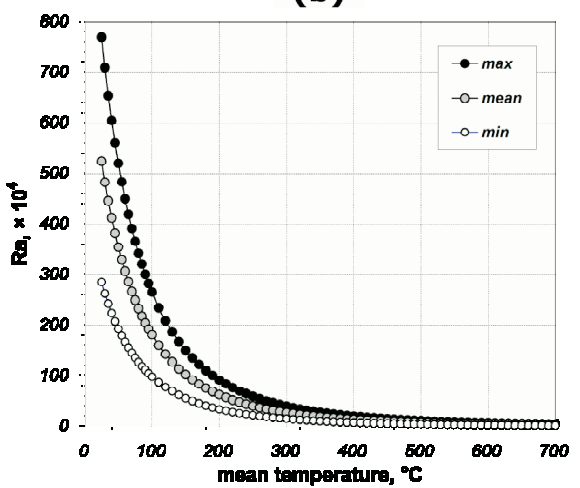

Figure 12: The Rayleigh number obtained for fixed values of the temperature difference $\Delta t$ : (a) values for the section $60 \mathrm{~mm} \mathrm{II,} \mathrm{(b)} \mathrm{values} \mathrm{for} \mathrm{the} \mathrm{section} 80 \mathrm{~mm}$.

Figure 12 presents the results of calculations obtained for constant values of the temperature difference. In this case, the profile of the curves is the most different compared to those presented in Fig. 8. This means that the 
characteristic profile of changes in the Ra number with respect to temperature is mainly attributable to changes in the parameter $\Delta t$. Figure 12 shows that, for constant $\Delta t$, Ra number decreases over the whole range of temperature. The curves obtained in this case are similar in their shape to equilateral hyperbolas.

\section{Summary}

The study demonstrated that the phenomenon of free convection in the area of rectangular steel sections is varying in terms of intensity. It was found that the highest intensity of this process occurs for the temperature of $100^{\circ} \mathrm{C}$. This is mainly caused by changes in the temperature difference observed in the area of sections and changes in kinematic coefficient of viscosity of air. The increase in the value of Ra criterion at the initial stage is attributable to changes in the parameter $\Delta t$. After exceeding of $100^{\circ} \mathrm{C}$, the main effect on convection is from changes in air viscosity. Thus, with further increase in temperature, the Rayleigh number starts to decline rapidly despite further rise in the difference in temperature. At the same time, it should be aware that the value of parameter $\Delta t$ depends on the other heat transfer mechanisms that are present in the analyzed system. These mechanisms include conduction in the wall of the section and thermal radiation between its surfaces and free convection. All these mechanisms are interrelated which makes that the course of convection depends on the section geometry and thermal properties of the steel. It should be noted that the share of conduction, radiation and convection in the total heat transfer change with the furnace temperature increase. Accurate evaluation of the quantitative contribution of these modes of heat transfer to the process of heating the section bundles will be the subject of future publications. However, for the temperature ranges used for heat treatment of steel sections, it should be emphasized that convection does not have a substantial effect on intensity of section bundles' heating. Finally it must be emphasized that the presented results refers to a very particular case and therefore, cannot be generalized. 


\section{References}

[1] Faterer G.F.: Heat Transfer in Single and Multiphase Systems. CRC Press LLC, Boca Raton, London, New York, Washington D.C., 2003.

[2] Bejan A.: Convection Heat Transfer, 4th Edn., Wiley 2013.

[3] Wiśniewski S., Wiśniewski S.T: Heat Transfer. PWN, Warsaw 2012 (in Polish).

[4] WyczóŁkowski S.: Modelling of steady free convection in two-dimensional enclosed space. Wydawnictwo Politechniki Częstochowskiej, Częstochowa 1998 (in Polish).

[5] Jaluria Y.: Natural Convection - Heat and Mass Transfer. Pergamon Press, Oxford, New York 1980.

[6] WyczóŁkowski R.: Classification and characterization of porous charges found in the industrial heat treatment practice. Hutnik - Wiadomosci Hutnicze 79(2012), 12, 877-879 (in Polish).

[7] Sverduin A.V., Ness, A.R.: Fundamental concepts in steel heat treatment. In: Steel Heat Treatment - Metallurgy and Technologies, Chap. 3 (G.E.Totten, Ed.), CRC Taylor \& Francis Group, Boca Raton, London, New York 2006.

[8] WyczóŁkowski R., Benduch A.: Effective thermal conductivity as a basic thermal property of steel porous charge. In: Current Problems in Electrical Power Engineering, Vol. III, Oficyna Wydawnicza Politechniki Wrocławskiej, Wrocław 2014.

[9] Kaviany M.: Principles of Heat Transfer in Porous Media. Springer-Verlag, New York 1991.

[10] WaKao N., Wato K.: Effective thermal conductivity of packed beds. J. Chem. Eng. 2(1968), 24-33.

[11] Van Antwerpen W., Du Toit C.G., Rousseau P.G.: A review of correlations to model the packing structure and effective thermal conductivity in packed beds of mono-sized spherical particles. Nucl. Eng. Des. 240(2010), 1803-1818.

[12] Cangel Y.A.: Heat Transfer - A Practical Approach, 2nd Edn. Mc Graw Hill, New York 2002

[13] WyczóŁkowski R., Musią D.: Experimental tests for the occurence of convective heat transfer within the bed of rectangular steel profiles. Arch. Thermodyn. 33(2012), 89-100.

[14] Wyczólkowski R., Musiae D.: The experimental study of natural convection within the space of a bundle of rectangular sections. Exp. Therm. Fluid Sci. 51(2013), $122-134$.

[15] WyczóŁKowski R.: Analysis of the Rayleigh number in the area of steel rectangular sections in the conditions of steady and unsteady heat flow. Civil Environ. Eng. Rep. 14(2014), 119-132.

[16] www.czaki.pl/en/ 